\title{
Physics fights back
}

\author{
The physical sciences are strongly favoured in President Bush's 2007 budget \\ request - but researchers can't count their chickens yet.
}

Praris resident George W. Bush's State of the Union address on 31 January has been widely reviewed as an uninspiring compendium of small things. But for those directly involved, some of these small things are highly meaningful. For US physicists, the president's public embrace of their work, and his pledge to double funding for it over the next decade, is arguably the best news in the 13 years since the discipline reeled from the cancellation of the Superconducting Supercollider in Texas in 1993.

Bush's unexpected embrace of physics was confirmed in the budget request that he sent to Congress earlier this week. The Department of Energy's Office of Science, which supports the bulk of physics research in the United States, will receive an overall budget increase of $14 \%$, should Congress accept Bush's proposal. Its high-energy physics programme will grow by $8 \%$ and its nuclearphysics programme (which funds basic research into atomic nuclei) expands by a spectacular $24 \%$. The National Science Foundation, which supports most non-biomedical research at US universities, also obtains a healthy $8 \%$ increase.

These increases are part of Bush's 'American Competitiveness Initiative', which will support more spending on research and education programmes that are deemed relevant to industrial competitiveness. Prompted by public crises at Ford and General Motors, as well as by a general sense of foreboding about China's growing industrial prowess, Congress has been stirring on this issue lately (see Nature 439, 517; 2006). It may therefore be generally indined to support the competitiveness initiative.

Even so, it is by no means certain that physicists will receive even the proposed increases for 2007, never mind the longer-term expansion promised in Bush's speech. This year's proposed cuts in science budgets at NASA demonstrate the danger of relying on bold new initiatives within a general context of fiscal restraint. In NASA's case, the president's plan to send astronauts to the Moon and eventually to Mars is beginning to resemble an albatross around the agency's neck.
It is conceivable that a similar scenario could yet play out at the Department of Energy. In Bush's budget proposal, the increases in science spending are offset by cuts in other programmes at the department, such as the clean-up of former nuclear-weapons plants. These cuts will be fiercely contested by the programmes' respective champions in the Congress.

In this context, advocates for the physical sciences will have their work cut out securing the 2007 spending levels that the president recommends. That

\section{"The competitiveness case for more investment in this arena is a powerful one."} said, the competitiveness case for more investment in this arena is a powerful one. As has been noted repeatedly in these pages, inadequate funding at the Office of Science has weakened US physics. It has also distorted the balance of US science spending, driving young people away from scientific work that would be intellectually rewarding, as well as being valuable to industrial competitiveness.

If the budget is approved by Congress, it will give the energy department a long-overdue opportunity to properly use facilities that it has built but can't afford to run. It will also provide more grant opportunities for physical scientists.

But only the long-term investment promised in the president's speech will enable the department to build a new generation of world-class facilities and restore the battered pride of its laboratories. The outlook for this is highly uncertain: the United States must contend with massive financial commitments for the US presence in Iraq and the repair of the hurricane-ravaged Gulf coast. Given the country's financial outlook, US physicists certainly can't bank on their budgets being doubled as the president suggests. Nevertheless, they should be grateful that, after a rocky period, their contribution to the nation is once again being recognized.

\section{Network of concern}

\section{Only biologists can effectively police the misuse of biological agents.}

7 he array of techniques and compounds that have the potential to be used in bioterror attacks is growing apace, and reaches far beyond a small number of obviously dangerous agents, such as anthrax spores.

At present, the threat is policed mainly by a handful of people in the military and at spy agencies. Interest in the issue has, since the attacks of 11 September 2001, been most acute in the United States.
But bioterrorism is a global threat and, ultimately, it is only vigilance by a much larger network of working biologists that can provide some reassurance in the face of it.

That is the central message of a report released on 31 January by the US Institute of Medicine (IOM). The document, Globalization, Biosecurity, and the Future of the Life Sciences, makes a convincing argument that much greater cooperation between scientists around the world will be needed to counter bioterrorism. To this end, it calls on scientists to create a global, grassroots network to discuss and monitor research that might be misused to kill and maim.

Scientists tend instinctively to favour independence and creativity - and to oppose monitoring and regulation. But there are circumstances in which it falls on the community to support 
precautionary vigilance over unbridled freedom of action.

The IOM panel, co-chaired by Stanley Lemon of the University of Texas at Galveston, envisages a global biosecurity network not dissimilar to ProMED-mail, a web- and e-mail-based network that helps public-health specialists worldwide share information.

Such a network would enable scientists to exchange views on questions, such as when the risks associated with a particular experiment outweigh its potential benefits. It is extremely difficult to make such calls, as was demonstrated most recently by last year's debate over a paper that modelled a toxin attack on the US milk supply (see Nature 435,$855 ; 2005)$. The Lemon report points out that a grassroots network of scientists interested in bioterrorism issues would at least get a broader section of the community talking and thinking about such issues.

The report also emphasizes the fact that the scope of the bioweapons threat is far wider than commonly imagined. We are entering an era in which scientists will be able to design and build organisms for purposes of their choice, for good or ill. The IOM rightly advises US policy-makers to broaden their consideration of biodefence beyond the 50-or-so 'select agents' that the US health department has concentrated on until now. That will involve greater consultation with researchers who operate in areas ranging from genetics to nanotechnology, and who do not consider themselves to be involved in biodefence work.

Finally, the IOM calls for more input of up-to-date scientific advice at the US national security agencies, such as the Central Intelligence Agency and the National Security Agency, who are charged with looking out for bioterror-related activity. The work of these agencies is classified, and the report calls for the establishment of a scientific advisory board, with appropriate clearances, to help the agencies interpret the data they collect. This idea was also proposed last March by a commission set up by President George Bush to look at the spy agencies' capabilities in countering weapons of mass destruction. It should be implemented as soon as is practicable.

The containment of potentially dangerous biological knowledge is a formidable challenge - intrinsically even tougher than blocking the proliferation of nuclear weapons. But it is not one that the scientific community can wish away. The IOM panel has performed a valuable service by highlighting some ways in which biologists can step up to it.

\section{Japan's research conduct}

\section{A framework is required for investigations into scientific misconduct in Japan.}

 or the past two years, researchers in Japan and elsewhere have been frustrated in their attempts to reproduce a set of RNA interference papers co-authored by Kazunari Taira, a biochemist at the University of Tokyo (see Nature 439, 514; 2006).

The university has now established a committee that will look into Taira's experiments. But some of those involved in the investigation admit that it may not get to the bottom of the issue. The episode points to a lack of preparation for such cases on the part of the university by far the country's largest and most prestigious research institution. Fault also lies with the government, which has failed to establish a robust framework for investigating alleged scientific misconduct. The lack of such a national framework leaves Japan's universities to look into such allegations independently, and on an ad hoc basis.

The case came to the fore last spring, when the RNA Society of Japan, prompted by members' complaints, requested the University of Tokyo to look into 12 papers produced by Taira's research team. Asked to provide evidence to back up the papers, the team said that it no longer had the notebooks containing the experimental data and that a computer, to which the data had been transferred, had broken down and the data had been erased. The team then struggled to comply with a request that some of its experiments be repeated. Taira has publidy blamed his co-author, Tokyo University biochemist Hiroaki Kawasaki, for mislaying the data. Both men deny any wrongdoing.

Members of a preliminary committee looking into the case complained that they were not given authority to investigate properly. A new committee set up two weeks ago says it will conduct interviews with many researchers on the team. But e-mail exchanges among the researchers will not be used as evidence, and one committee member admits that, without the notebooks, a determination of whether scientific misconduct occurred is improbable. Committee member Kimihiko Hirao, head the university's school of engineering, says that, unlike the South Korean case of Seoul National University's Woo Suk Hwang, where inside informers pushed the investigation along, they have no direct allegations of misconduct to investigate.

Things could have gone differently. The university did not have a system for accepting and protecting whistleblowers, and therefore could not really expect inside informers to come forward even if misconduct had occurred. There are no clear rules on the penalty if documentation, such as laboratory notebooks or other materials essential to supporting experimental results, is destroyed. And there is no established framework within which such an investigation should proceed.

The University of Tokyo has argued that it lacks the
"A country of Japan's scientific muscle ought to have set up a body to train universities to investigate fraud." power to investigate the case properly. But two years ago, like Japan's other national universities, it received widespread autonomy from the government. It should use this autonomy to recover from the damage done to its reputation by its unsteady response to this case.

Universities in the United States and Europe have, sometimes with the aid of national misconduct offices such as the US Office of Research Integrity, developed mechanisms allowing them to investigate such cases discretely and comprehensively. A country of Japan's scientific muscle ought to have set up such a body to train universities to investigate fraud and, where appropriate, to administer national sanctions.

Investigations into research misconduct are invariably uncomfortable for all concerned. But the alternative is the pervasive aroma left by cases such as this one, in which the researchers and institutions are neither convicted nor exonerated. It is to be hoped that the investigation now belatedly under way will clear the air. 